\title{
ASPECTOS DA ANATOMIA E DO ÓLEO ESSENCIAL EM FOLHAS DE PINDAÍBA (Xylopia brasiliensis Spreng.) ${ }^{1}$
}

\author{
Aspects of the anatomy and essential oil in leaves of pindaíba (Xylopia brasiliensis Spreng.) \\ Breno Régis Santos ${ }^{2}$, Renato Paiva ${ }^{3}$, Evaristo Mauro de Castro ${ }^{4}$, Maria das Graças Cardoso ${ }^{5}$, \\ Rodrigo Kelson Silva Rezende ${ }^{6}$, Patrícia Duarte de Oliveira Paiva ${ }^{7}$
}

\section{RESUMO}

Neste trabalho, estudaram-se aspectos de anatomia foliar, extraiu-se e caracterizou-se o óleo essencial presente nos tecidos foliares de pindaíba (Xylopia brasiliensis). Os cortes transversais foram realizados à mão livre com o auxílio de uma lâmina de barbear e submetidos ao processo de coloração com safranina e azul de astra. A extração e a caracterização do óleo essencial foram realizadas pela técnica de arraste de vapor de água. Na seção transversal da folha da pindaíba foi observada a presença de cavidade oleífera, sendo o óleo constituído principalmente de óxido de cariofileno.

Termos para indexação: Pindaíba, anatomia foliar, óleo essencial, cariofileno.

\section{ABSTRACT}

Aspects of leaf anatomy, extraction and characterization of essential oils present in leaf tissues of Pindaíba (Xylopia brasiliensis), were studied. The anatomical cuts were manually performed and their visualization were made through a coloration process using safranine and astra blue. The extraction and characterization of the essential oil used the steam drag's method. With these studies it was observed the presence of oily idioblasts filled mainly with cariophylene oxide.

Index Terms: Pindaíba, leaf anatomy, essential oil, cariophylene.

(Recebido para publicação em 10 de fevereiro de 2003 e aprovado em 8 de setembro de 2003)

\section{INTRODUÇÃO}

Os processos vitais de biossíntese são responsáveis pela formação, acúmulo e degradação de inúmeras substâncias orgânicas no interior das células que formam os diversos tecidos dos organismos animais e vegetais. Muitas dessas substâncias, especialmente as de origem vegetal, são usadas em diversas áreas aplicadas à alimentação e saúde, o que tem estimulado estudos fitoquímicos de várias espécies.

O estudo fitoquímico de uma espécie vegetal pode revelar a ocorrência de substâncias de interesses diversos para o homem, as quais, após serem caracterizadas, podem ser usadas de diversas formas.

As substâncias responsáveis pelos aromas, sendo de origem natural ou sintética, são conhecidos como essência, óleo essencial. Além da utilização industrial na produção de perfumes e cosméticos, os óleos essenciais têm sido utilizados como fármacos e no combate a fungos e bactérias (CARDOSO et al., 2000). Os óleos essenciais apresentam importâncias ecológicas, especialmente como inibidores da germinação, proteção contra predadores, atração de polinizadores, proteção contra perda de água e aumento da temperatura (CRAVEIRO e MACHADO, 1986; HARBONE, 1993).

No presente trabalho, é feito o estudo de aspectos da anatomia foliar, extração e caracterização do óleo essencial presente em tecidos foliares de pindaíba (Xylopia brasiliensis Speng., Família Annonaceae), uma espécie nativa encontrada do sul da Bahia até o Rio Grande do Sul (em floresta pluvial da encosta atlântica), que pode ser um grande potencial medicinal e industrial.

\section{MATERIAL E MÉTODOS}

O material vegetal foi constituído de folhas coletadas de forma homogênea no terço médio de plantas de 2 anos de idade mantidas em casa-de-vegetação, sob irradiância de fótons de $600 \mu \mathrm{mol} \mathrm{s} \mathrm{m}^{-1}$, utilizando-se sombrite $50 \%$.

\footnotetext{
1. Trabalho com apoio financeiro da Fundação de Amparo àPesquisa do Estado de Minas Gerais/FAPEMIG.

2. Engenheiro Agrônomo, M.Sc, Departamento de Biologia. Universidade Federal de Lavras/UFLA, Caixa Postal 37 - $37200-000$ - Lavras, MG. brenors@yahoo.com.br;

3. Professor Adjunto, PhD, Departamento de Biologia/UFLA

4. Professora Adjunto, Dra., Departamento de Química/UFLA

5. Professor Adjunto, Dr., Departamento de Biologia/UFLA.

6. Bolsista de Iniciação Científica (PIBIC/CNPq), Departamento de Biologia/UFLA.

7. Professora Adjunto, Dra., Departamento de Agricultura/UFLA.
} 
Após a coleta, as folhas foram fixas em formaldeído, ácido acético e álcool etílico (F.A.A.) $70 \%$ por 72 horas e, posteriormente, conservadas em álcool etílico $70^{\circ} \mathrm{GL}$, segundo Johansen (1940).

Os cortes transversais da região mediana da folha foram realizados à mão livre com auxílio de uma lâmina de barbear e submetidos ao processo de coloração com uma mistura de safranina e azul de astra (KRAUS e ARDUIN, 1997). Os cortes foram montados em lâminas semipermanentes com água glicerinada.

As fotomicrografias foram obtidas utilizando-se um fotomicroscópio Olympus BX-60 existente no Laboratório de Citologia do Departamento de Biologia da Universidade Federal de Lavras.

A extração e caracterização do óleo essencial foram realizadas no Laboratório de Química Orgânica do Departamento de Química da Universidade Federal de Lavras. Pesaram-se $30 \mathrm{~g}$ de folhas frescas e pela técnica de arraste de vapor de água, extraiu-se o óleo essencial. Esse processo durou 1,5 hora, obtendo-se 1,0 litro de hidrolato. Esse foi particionado com diclorometano $\left(\mathrm{CH}_{2} \mathrm{Cl}_{2}\right)$, separando-se a fase aquosa da orgânica. Após as frações orgânicas serem reunidas, adicionou-se sulfato de magnésio anidro, para retirar qualquer excesso de água. Filtrou-se, levando o filtrado para evaporação em evaporador rotatório, obtendo-se o óleo puro. O óleo obtido foi submetido a uma análise espectrométrica, utilizando-se um aparelho de infravermelho e um espectrofotômetro de massa.

\section{RESULTADOS E DISCUSSÃO}

\section{Aspectos da Morfologia Interna da Folha}

A lâmina foliar possui organização dorsiventral (Figura 1). Em seção transversal, ao nível do terço superior das folhas, a lâmina foliar exibe epidermes unisseriadas. $\mathrm{O}$ mesofilo apresenta 1 a 2 camadas de parênquima paliçádico e 4 a 5 camadas de parênquima esponjoso. No mesofilo, observou-se também a presença de cavidade secretora com uma concentração maior no parênquima esponjoso com óleo no interior dessas cavidades, as quais reagiram positivamente ao teste para lipídios com Sudan IV. (Figuras 1A e 1B); como não foram realizados estudos ontogenéticos, não é possível estabelecer o tipo de origem dessas cavidades, possivelmente lisígena. Segundo Simões et al. (2001), os óleos essenciais podem ocorrer em estruturas secretoras especializadas, tais como em pêlos glandulares (Lamiaceae), células parenquimáticas diferenciadas (Lauraceae, Piperaceae, Poaceae), canais oleíferos (Apiaceae) ou em cavidades lisígenas ou esquizolisígenas (Pinaceae, Rutaceae).

\section{Aspectos do óleo essencial}

Obteve-se, após a extração do óleo essencial da Pindaíba, um rendimento de $0,4 \%$. Pelos resultados de infravermelho (Figura 3), observou-se um sinal fraco na faixa de $3400-3600 \mathrm{~cm}^{-1}$, o qual, segundo Silverstein et al. (1994), pode ser atribuído à presença de uma hidroxila alcoólica secundária ou terciária ou de um éter conjugado, confirmado pelo sinal em $1261 \mathrm{~cm}^{-1}$. Na faixa compreendida entre $2700-3000$ $\mathrm{cm}^{-1}$, observou-se um sinal característico de grupos metilas, metilenos e metínicos.

Após o estudo com o infra-vermelho, realizou-se a análise de espectro de massa, demonstrando que o composto "óxido de cariofileno" apresentou-se com $92 \%$ de probabilidade de ser o composto majoritário no óleo presente em tecidos foliares de pindaíba.

$\mathrm{O}$ composto cariofileno $\mathrm{C}_{15} \mathrm{H}_{24}$ (Figura 4) é produzido pelas plantas na rota metabólica dos terpenos, sendo também encontrado no óleo essencial de cravoda-índia (BARBOSA, 1998). Craveiro et al. (1981) ressaltaram que em Annona squamosa L. é encontrado o cariofileno em seu óleo essencial, com um rendimento de $0,4 \%$ e um teor de $63 \%$. O carifileno pode ser encontrado também no óleo essencial de Copaífera langsdorfii Desf. (FEIBERT e LANGENHEIM, 1988).

Segundo Barbosa (1998), os óleos essenciais apresentam atividades medicinais, podendo ser utilizados, de acordo com suas características, para diversas finalidades. O óleo essencial cariofileno, segundo Haslam (1996), pode ser empregado na medicina tradicional como remédio, para o tratamento de diversas moléstias orgânicas. 


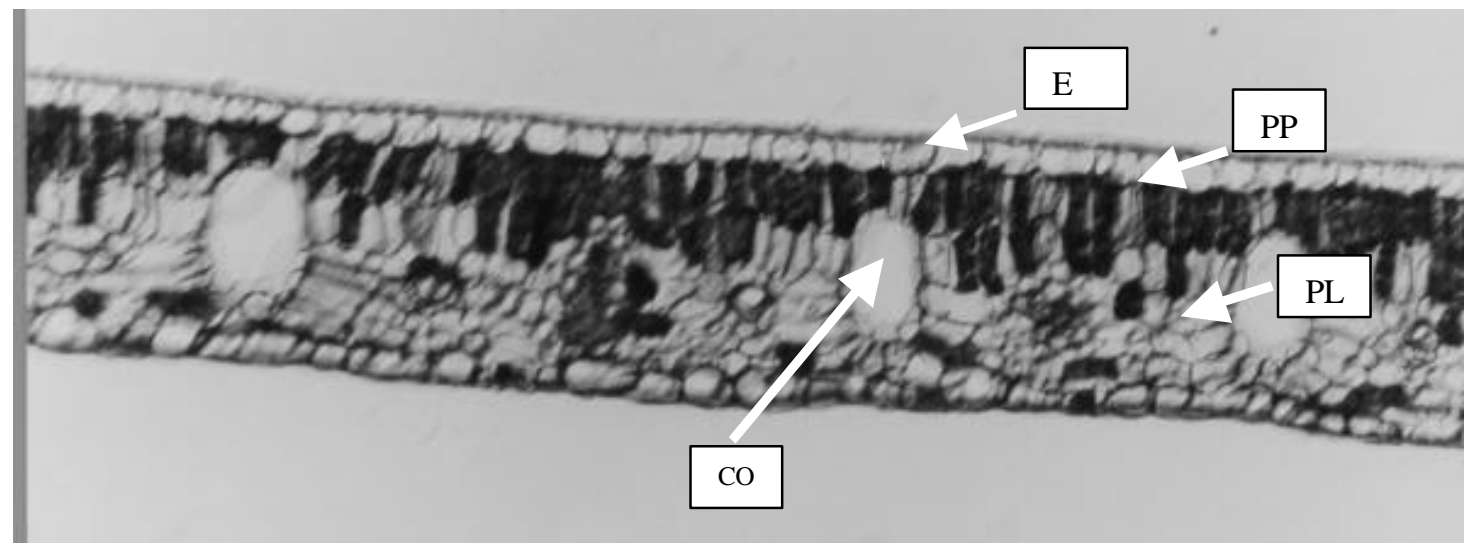

FIGURA 1 - Seção transversal do limbo foliar de Pindaíba. Epiderme uniestratificada (E), parênquima paliçádico (PP), parênquima lacunoso (PL), Cavidade oleífera (CO).

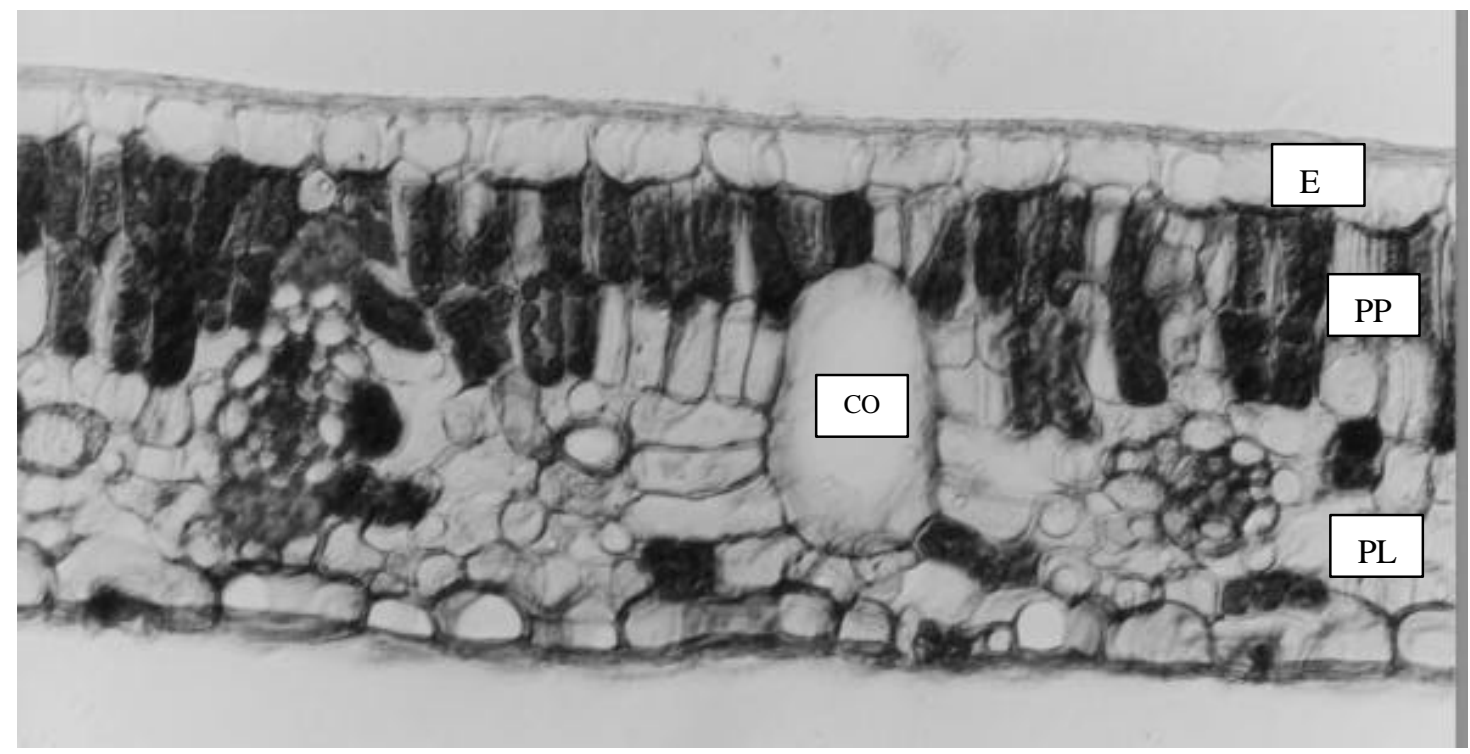

FIGURA 2 - Detalhe da seção transversal do limbo foliar de Pindaíba. Epiderme uniestratificada (E), parênquima paliçádico (PP), parênquima lacunoso (PL), Cavidade oleífera (CO). 


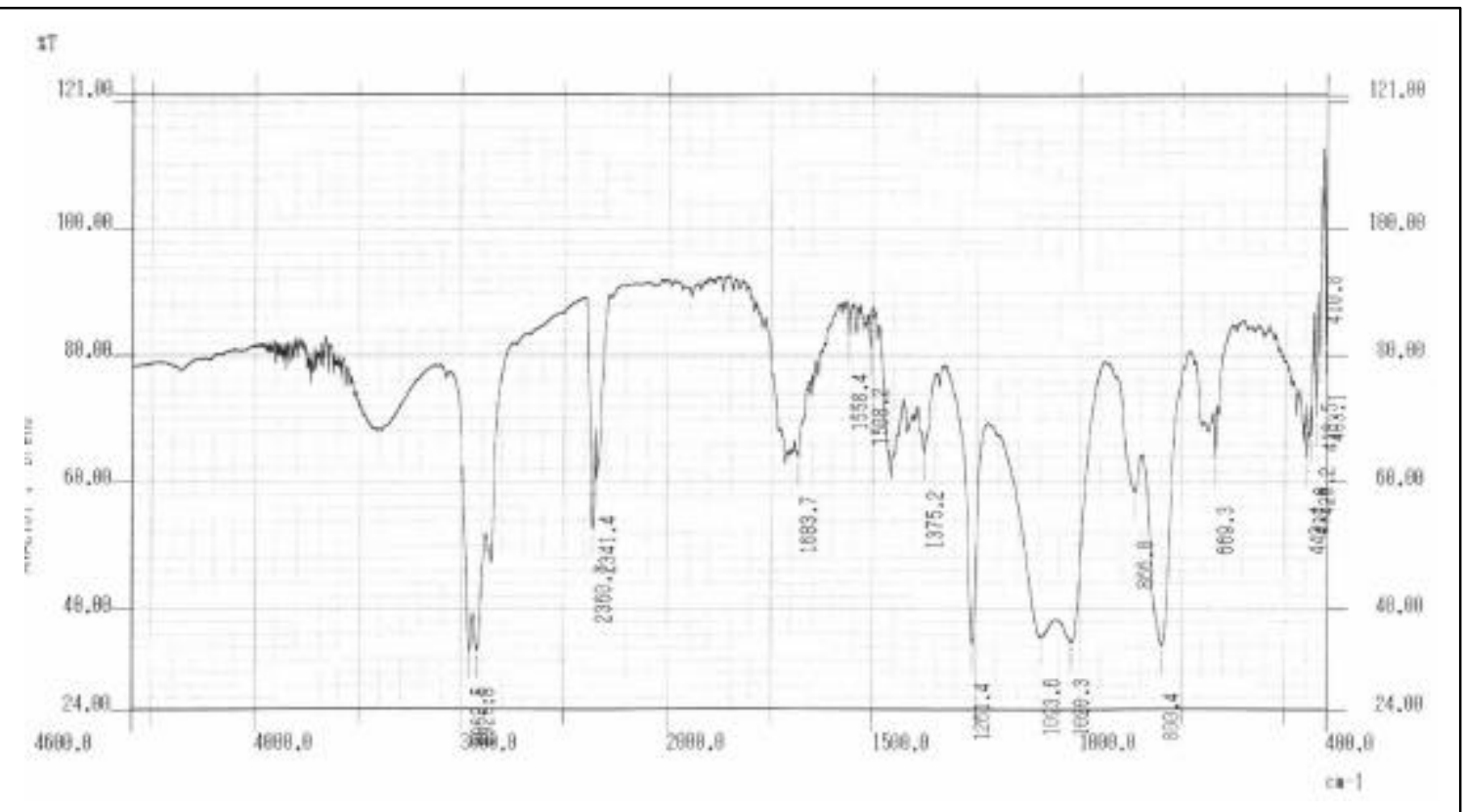

FIGURA 3 - Espectro de infravermelho do óleo essencial extraído das folhas de Xylopia brasiliensis.

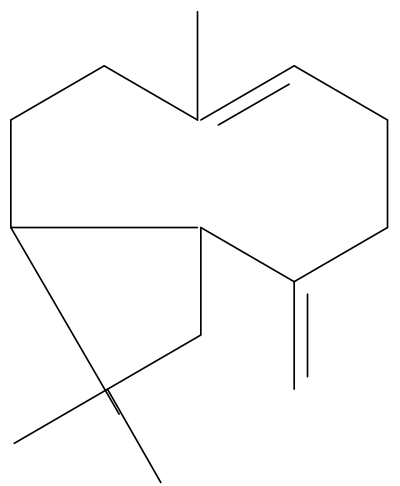

FIGURA 4 - Fórmula estrutural de um $\beta$ - cariofileno Fonte: (SIMÕES et al., 2001).

\section{CONCLUSÕES}

Em relação às características anatômicas da folha, pode-se verificar a presença de cavidade secretora de óleo essencial no mesofilo.

Mediante sistema de arraste a vapor de água, foi possível obter óleo essencial de pindaíba.
O provável constituinte majoritário do óleo essencial obtido de folhas de pindaíba é o óxido de cariofileno.

\section{REFERÊNCIAS BIBLIOGRÁFICAS}

BARBOSA, L. C. A. Química orgânica: uma introdução para as ciências agrárias e biológicas. Viçosa: UFV, 1998. p. 354.

Ciênc. agrotec., Lavras, v. 28, n. 2, p. 345-349, mar./abr., 2004 
CARDOSO, M. G.; GAVILANES, M. L.; MARQUES, M. C. S.; SHAN, A. Y. K. V.; SANTOS, B. R.; OLIVEIRA, A. C. B.; BERTOLUCCI, V. K. S.; PINTO, A. P. S. Óleos essenciais. Lavras: UFLA/PROEX, 2000. 42 p. (Boletim de Extensão, 73).

CRAVEIRO, A. A.; FERNANDES, A. G.; ANDRADE, C. H. S.; MATOS, F. J. A.; ALENCAR, J. W.; MACHADO, M. I. L. Óleos essenciais de plantas do nordeste. [S.1.]: UFC, 1981. 210 p.

CRAVEIRO, A. A.; MACHADO, M. I. L. De aromas, insetos e plantas. Ciência Hoje, São Paulo, v. 4, n. 23, p. 54-63, 1986.

FEIBERT, E. B.; LANGENHEIM, J. H. Leaf resin variation in Copaifera langsdorffi: relation to irradiance and herbivory. Phytochemistry, Great Britain, v. 7, n. 8, p. 2527-2532, 1988.

HARBONE, J. B. Ecological biochemistry. 4. ed. London: Academic, 1993.

HASLAM, E. Natural polyphenols (vegetable tannins) as drugs and medicines: possible modes of action. Journal of Natural Products, Chicago, v. 59, p. 205-215, 1996.
JOHANSEN, D. A. Plant microtechnique. New York: Mac-Graw Hill Book, 1940. 523 p.

KRAUS, J. E.; ARDUIN M. Manual básico de métodos em morfologia vegetal. Rio de Janeiro: EDUR, 1997. $198 \mathrm{p}$.

SILVERSTEIN, R. M.; BASSLER, G. C.; MORRIL, T. C. Indentificação espectrometria de compostos orgânicos. Rio de Janeiro: Guanabara Dois, 1994.

SIMÕES, C. M. O.; SCHENKEL, E. P.; GOSMANN, G.; MELlO, J. C. P.; MENTZ, L. A.; PETROVICK, P. R. Farmacognosia: da planta ao medicamento. Florianópolis: UFSC, 2001. $821 \mathrm{p}$. 